\title{
A STUDY ON THE EXCITATION-CONTRACTION COUPLING OF THE BULLFROG VENTRICLE WITH VOLTAGE CLAMP TECHNIQUE
}

\author{
Masayosi Goto, Yosiko Kıмото and Yuki Kato \\ Department of Physiology, School of Medicine, Kyushu University, Fukuoka, Japan
}

\begin{abstract}
Summary 1. The membrane potentials, currents and contractile responses were measured in the bullfrog ventricular trabeculae under voltage clamp conditions by means of double glycerol-gap technique. 2. The threshold potential for sodium inward current was $-62 \mathrm{mV}$ and that for tetrodotoxin insensitive current, $-58 \mathrm{mV}$. At stronger depolarization up to $+20 \mathrm{mV}$, the contractile tension increased, showing a sigmoid curve in the presence of tetrodotoxin.

3. The tension development depended strongly on the duration of depolarization. Below a critical duration, neither active current nor tension was elicited (Phase I). Slightly longer depolarization, up to about $100 \mathrm{msec}$, produced an all-or-none inward current and small tension in normal conditions (Phase II). This changed into graded responses after tetrodotoxin.

4. Further increase in duration of depolarization augmented the peak tension, first by increasing the rate of rise of tension (Phase III) and later by prolonging the time to peak tension (Phase IV). After reaching the peak the tensionde creased gradually when the depolarization was continued further (Phase V). No second rise of tension was observed for long and strong depolarizations.

5. Differences in characteristics of the bullfrog ventricle from those of mammalian myocardium were discussed, and a role of sarcotubular systems in the relation between the action potential and tension development was suggested.
\end{abstract}

Fundamental information relating membrane voltage to contractile tension in myocardium was first obtained by examining the potassium contracture of the muscle (LütTgau and Niedergerke, 1958; Lüttgau, 1964). Studies on the relation have also been done by altering the membrane potential by current application (Kavaler, 1959; WoOd et al., 1969; ANTONi et al., 1969; Goto and

Received for publication October 15, 1970

後藤昌義, 木元良子, 加藤由紀 
BrooKs, 1970). The most quantitative analysis, however, has been achieved on mammalian ventricles when the membrane potential was controlled accurately by the voltage clamp technique (Morad and Trautwein, 1968; Fozzard and Hellam, 1968; Reuter and Beeler, 1969; Beeler and Reuter, 1970 a, b, c).

No corresponding study with this technique, however, has been done so far on the myocardial contractility of cold-blooded animals in which distinct differences in the excitation-contraction (E-C) coupling are known (BRADY, 1964; STALEY and Benson, 1968). On the frog atrial muscle, Rougier et al. $(1968,1969)$ and BROWN and NoBle (1969) extensively analysed the membrane currents with the double sucrose-gap technique. The present authors have dealt with an analysis of the relationship between the membrane voltage and contraction of the bullfrog ventricle under voltage clamp conditions.

\section{METHODS}

The ventricle of the bullfrog, Rana catesbiana, was used. When the ventricle was isolated and opened, ventricular trabeculae which run to the atrio-ventricular valves were seen. A thin strip of those fiber bundles which appeared as parallel and unbranched as possible was isolated under a binocular microscope. The length of the strip was about $4 \mathrm{~mm}$, and the diameter, $0.6-0.8 \mathrm{~mm}$. The preparation was mounted in a perfusion bath at room temperature $\left(21-25^{\circ} \mathrm{C}\right)$.

The bath consisted of five Lucite compartments (1, 2, 3, 4 and 5) which were separated by four rubber membranes. Compartments 1,3 and 5 had $\mathrm{Ag}-\mathrm{AgCl}$ plate electrodes $E_{1}, E_{2}$, and $E_{3}$, respectively. Figure 1 shows a schematic diagram of the bath and experimental circuit. The preparation was pulled, valvular end first, through tightly fitting holes in the rubber membranes. The large terminal compartments ( 1 and 5) were filled with $200 \mathrm{~mm} \mathrm{KCl}$ solution to produce complete depolarization (LÜTTGAU, 1964). Isotonic glycerol solution flowed continuously through the intermediate compartments (2 and 4) and normal or test solutions through the central compartment (3). The advantage of using glycerol solution instead of sucrose was that the diffusion rate of glycerol was fast enough to minimize stray currents but slow enough to penetrate the muscle membrane (see CAPUTO, 1968).

The width of each glycerol gap was $1 \mathrm{~mm}$ and that of the central compartment was $0.3 \mathrm{~mm}$. This was the smallest value that could be used for stable tension recording. The value was almost the same as the space constant, $0.37 \mathrm{~mm}$, of the frog ventricle (VAN DER KLOOT and DANE, 1964) and produced a considerable error in voltage determination. However, when the strip within the gap was treated as an open circuited short cable (WeIDMANN, 1952; Brown and Noble, 1969), the maximum error estimated was of the order of $\pm 13 \%$. The voltage determined in a preparation was found to be extremely stable and reversible.

For measurement of tension, the valvular end of the muscle was attached to 


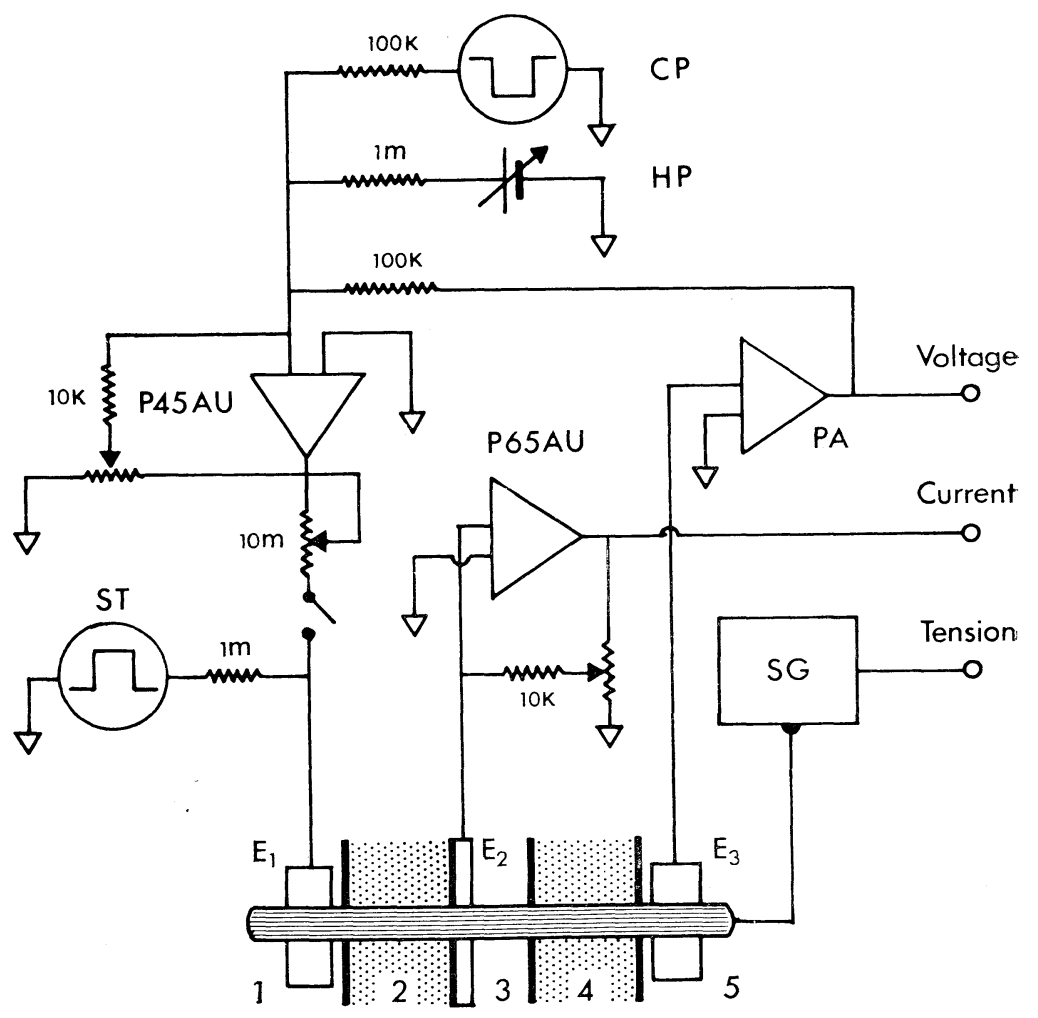

Fig. 1. Schematic illustration of experimental circuit and chamber. The chamber consists of five compartments $(1,2,3,4$ and 5). Thick vertical lines show rubber membranes and white rectangles, $\mathrm{Ag}-\mathrm{AgCl}$ plate electrodes $\left(\mathrm{E}_{1}, \mathrm{E}_{2}\right.$ and $\left.\mathrm{E}_{3}\right)$. The experimental circuit consists of four sections, voltage, current and tension measurements and voltage clamp system. See further explanations in the text. CP: Command pulse. HP: Holding potential. ST: Stimulator. SG: Strain gauge for tension measurement. PA: High input impedance preamplifier for voltage measurement. P65AU and P45AU: Operational amplifiers (Philbrick) for current measurement and current application, respectively.

the sensitive arm of a strain gauge (Nihon Kohden, SB-1T). The muscle, which was tightly fixed at the hole in the central electrode $\left(E_{2}\right)$, was loaded with about $0.1 \mathrm{~g}$ so that it would develop optimal tension during stimulation. The tension obtained, however, was not isometric but rather isotonic, since relatively long inert muscle segments in the compartments 4 and 5 were present in series.

The experimental circuits for the voltage, current measurements and voltage clamp system were modifications of those used by ANDERSON (1969) on uterine smooth muscle. The membrane potential was obtained as the potential difference between the electrodes $\mathrm{E}_{2}$ and $\mathrm{E}_{3}$. The potential, after amplification to about ten times with a high input impedance preamplifier (Nihon Kohden, MZ-3B), 
was compared with the desired potentials of clamp pulse (CP) and holding potential (HP) by adding the three voltages at the summing point of a high gain, inverting operational amplifier (Philbrick, P45AU). The output of this amplifier was connected to the electrode $\mathrm{E}_{1}$ through a safety resistance and switch. When the switch was closed and the resistance was shorted, the circuit was in voltage clamp condition. The central compartment (3) was kept at nearly earth potential by the aid of an operational amplifier (Philbrick, P65AU), which was used for current measurement.

The membrane potential, current and tension were displayed on a triad-beam oscilloscope (Nihon Kohden, VC-7) and the features were recorded simultaneously with a conventional long recording camera and an inkwriting oscillograph.

\section{RESULTS}

\section{1) Active inward current and strength-duration curve}

Figure 2A illustrates a few records of threshold determination with short (10 msec) and long (1000 msec) clamp pulses. The short voltage pulses appeared rectangular enough for our experimental purpose, showing a rise and fall time constant of less than $0.5 \mathrm{msec}$. Corresponding current records show capacitive and stray currents together with all-or-none appearance of active inward current when the clamp voltage exceeded a critical level. The latency of the inward current shortened with increasing voltage of the clamp pulse, however, the peak current and time to the peak remained unchanged. The current was usually a few ten $\mu \mathrm{A}$ and the time to the peak was $20-30 \mathrm{msec}$ in our preparations. With longer clamp pulses similar characteristics were also observed at threshold levels, although the active inward current was more or less affected by long continuing depolarization, and repetitive firing often occurred slightly above the threshold potential (arrow).

When tetrodotoxin $\left(10^{-6} \mathrm{~g} / \mathrm{ml}\right)$ was applied, the fast component of the inward current diminished, the slow one remaining as expected (see Fig. 3). The fast inward current was therefore due to sodium current and the slow one, to calcium or tetrodotoxin insensitive sodium current (RougIER et al., 1969).

A strength-duration curve obtained in normal solution is illustrated in Fig. 2B. In determining the curve, pulses which exceeded the threshold by more than a few $\mathrm{mV}$ were avoided (ADRIAN et al., 1969), and the mean values for three preparations were plotted. As seen in the figure, the rheobase appeared at about $62 \mathrm{mV}$, the utilization time was more than $200 \mathrm{msec}$ and the chronaxie was 9.8 msec. Tetrodotoxin $\left(10^{-6} \mathrm{~g} / \mathrm{ml}\right)$ produced a slight rise in rheobase $(58 \mathrm{mV})$. Examination with Weiss's formula, however, could not be made on this curve, since the abscissa of our figure is membrane voltage instead of current and a nonlinearity of voltage-current relationship was apparent in the bullfrog ventricle (see Fig. 5). 


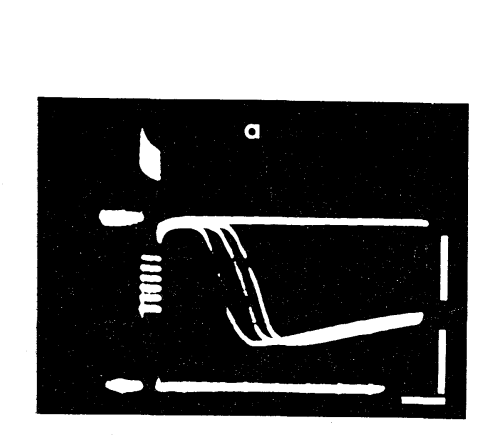

\section{A}
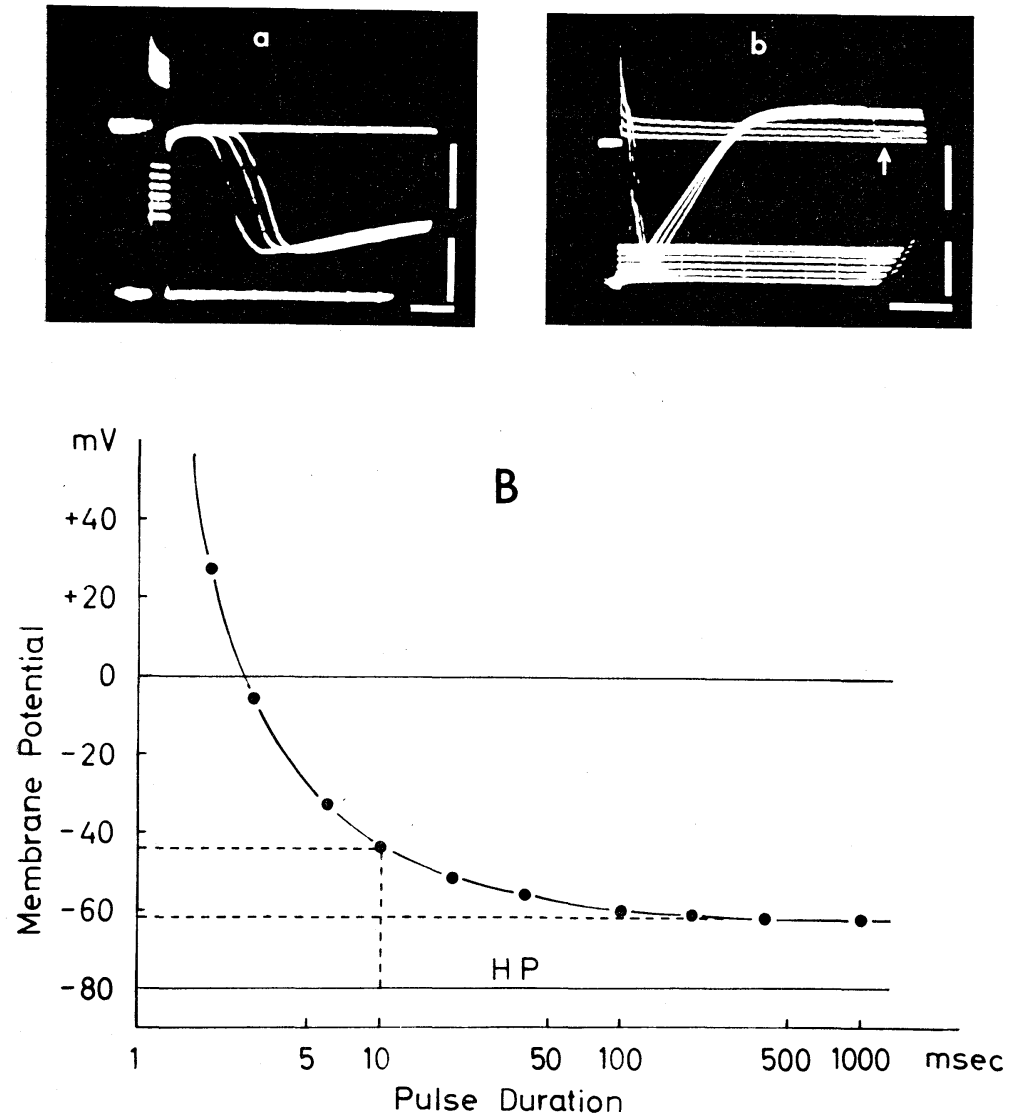

Fig. 2. A) Superimposed records of the currents and voltages at threshold levels under voltage clamped condition. a, Examination with short pulses, and $b$, with long pulses. In both cases, upper traces are currents, and lower traces, potentials. Vertical bars are calibrations of $10 \mu \mathrm{A}$ and $30 \mathrm{mV}$, and horizontal bars indicating time, $20 \mathrm{msec}$ for $\mathrm{a}$ and $100 \mathrm{msec}$ for $\mathrm{b}$. An arrow in $\mathrm{b}$ denotes the appearance of repetitive response. B) Strength-duration curve on the bullfrog trabeculae at $21^{\circ} \mathrm{C}$. Mean values of measurements from three preparations were plotted. HP: Holding potential $(-80 \mathrm{mV})$.

These observations raise several problems of interest. There are definite threshold durations and membrane voltages for initiation of the inward current. Although these are not fixed, requiring greater depolarization, when the duration of depolarization is shorter, the strength-duration curve may indicate a minimum charge transfer across the membrane for the initiation of the current (SANDOw, 1970). The inward current also begins with a definite delay after depolarization, which shortened with strength and duration of the depolarization. The delay may 
indicate the presence of some activation time for the initiation. The rising phase of the inward current is much faster than the falling phase and the total duration of the current amounts to $250-350 \mathrm{msec}$ at the holding potential level. The details of these characteristics in relation to tension development are under investigation.

\section{2) Effects of duration of pulses on the tension}

Change in duration of clamp pulse produced a marked influence on tension development. Typical results are shown in Figs. 3 and 4. The pulse duration was lengthened from $1 \mathrm{msec}$ to $4 \mathrm{sec}$ keeping the holding potential $(-80 \mathrm{mV})$ and depolarizing pulse $(-30 \mathrm{mV})$ constant.

Below a critical duration, neither active current nor tension was produced (Phase 1). When the pulse was lengthened over the critical duration, a small but all-or-none type tension response was elicited together with sudden appearance of inward current (Fig. 3A). A steady state contraction was attained immediately in the bullfrog ventricle. The peak tension did not increase markedly until the pulse duration reached $100 \mathrm{msec}$, almost twenty times longer than the threshold
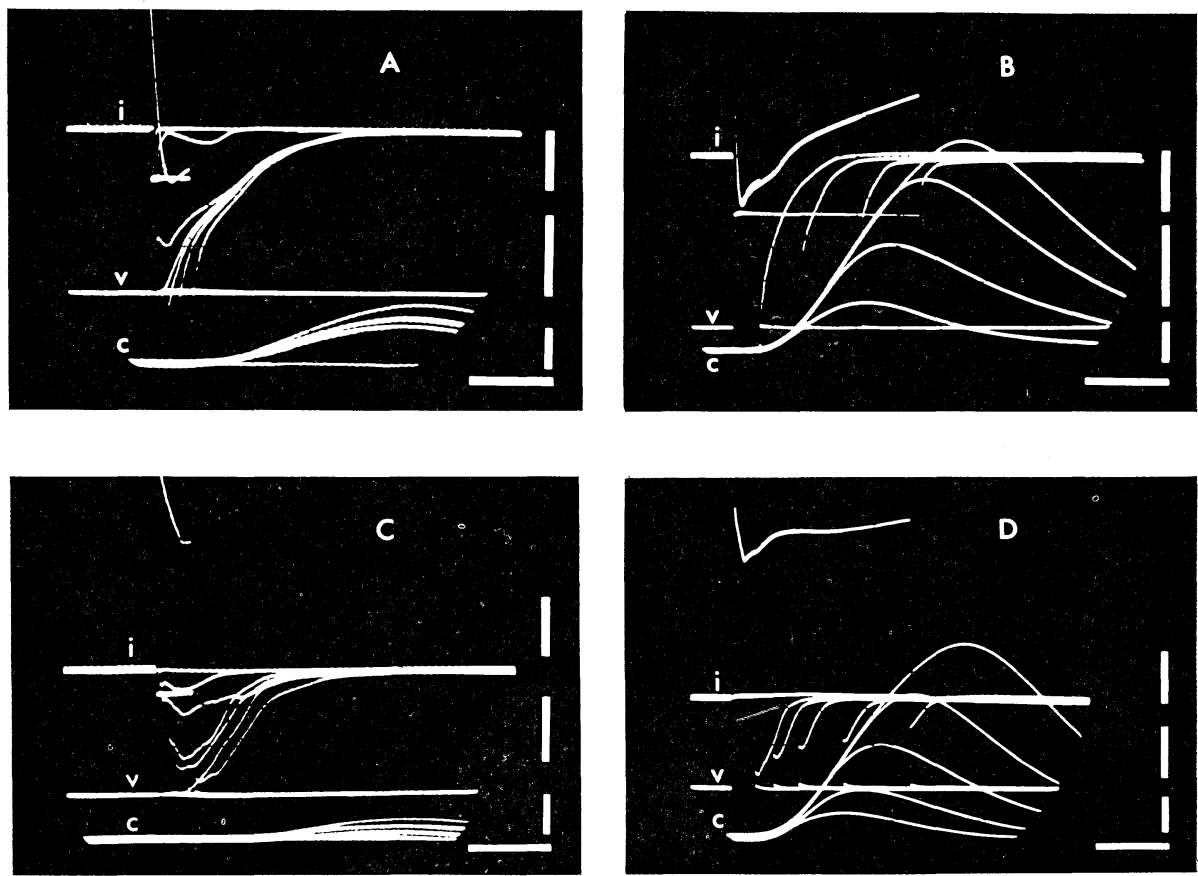

Fig. 3. Responses to depolarizing pulses of increasing duration. A) Effects of short pulses, 1, 2, 6, 10, 20, 60 and 100 msec durations. B) Those of $150-1000 \mathrm{msec}$ pulses. C, D) Similar experiments as A and B but in the presence of tetrodotoxin $\left(10^{-6} \mathrm{~g} / \mathrm{ml}\right)$. Horizontal bars are calibration of time, $200 \mathrm{msec}$ for $\mathrm{A}$ and $\mathrm{C}$, and $400 \mathrm{msec}$ for B and D. Vertical bars are those of $30 \mathrm{mV}, 10 \mu \mathrm{A}$ and $0.02 \mathrm{~g}$ for all voltage (v), current (i) and tension (c) records, respectively. 
duration (Phase II). This might be ascribed to the appearance of all-or-none inward current of almost constant size and duration, since, when tetrodotoxin $\left(10^{-6} \mathrm{~g} / \mathrm{ml}\right)$ was introduced, the inward current as well as tension development were markedly depressed to produce graded responses (Fig. 3C). The critical duration for generation of the current, however, was not changed markedly at this concentration of the drug.

Further increase of pulse duration above $100 \mathrm{msec}$ produced a marked increase of peak tension in the case of either the normal or treated preparations (Phase III, Fig. 3B, D). The increment of tension in this phase was mainly due to an increase in the rate of rise of tension development. However, the rate of rise of tension became constant for pulses longer than $300 \mathrm{msec}$ (Phase IV). The cause of the increment in this later phase was ascribed to a prolongation of the active state. Up to about $2 \mathrm{sec}$ of pulse duration, peak tension was always
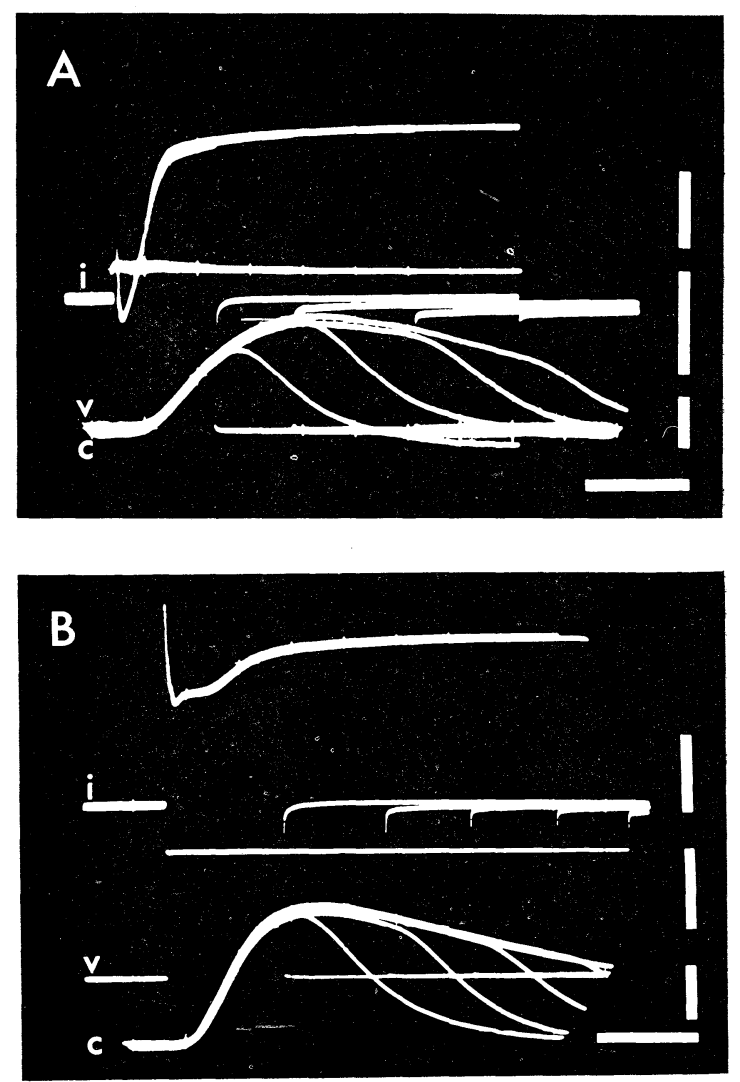

Fig. 4. Effects of long pulses on the current and tension development. A) Under normal conditions, and B) after tetrodotoxin $\left(10^{-6} \mathrm{~g} / \mathrm{ml}\right)$. Horizontal bar denotes $1 \mathrm{sec}$. Vertical bars are calibrations of $30 \mathrm{mV}, 10 \mu \mathrm{A}$ and $0.08 \mathrm{~g}$. 
attained after the pulse with a considerable delay. These different phases elucidated accord quite well with those discriminated by the method in which the action potential was abolished by anodal polarization at various times (KAWATA et al., 1969).

The inward current observed after pulses (after-inward current) consisted of at least two components, as can be seen in the figure. The fast one showed a time constant of about $0.2 \mathrm{sec}$ and the slow one, a time constant of a few seconds. BROWN and NoBLE (1969) have extensively analysed the nature of these currents in the frog atrium.

When the pulse was lengthened to more than $2 \mathrm{sec}$, the peak tension was attained during the pulse and a gradual decrease of tension followed (Phase $\mathrm{V}$, Fig. 4). After termination of the pulse, the fall of tension was accelerated. Two components of the after-inward current were also observable. The fast component was gradually depressed with prolongation of the pulse while the slow component was augmented.

A graphical summary of the effects of pulse duration on the tension development is illustrated in Fig. 6A.

\section{3) Relation between peak tension and membrane potential}

Figure 5 shows the tension development of the muscle when the membrane potential was changed from the holding potential $(-70 \mathrm{mV})$ to various other clamped levels. Step depolarization produced no tension until the membrane potential reached a critical level. A steep increase in tension occurred between -55 and $-20 \mathrm{mV}$ in normal solution and maximum tension was attained between +20 and $+30 \mathrm{mV}$.

The relation between the developed tension and membrane potential is illustrated in Fig. 6B, in which the tension scale is normalized. In normal Ringer solution, the relationship was not necessarily sigmoid (filled circles). However, when tetrodotoxin $\left(10^{-6} \mathrm{~g} / \mathrm{ml}\right)$ was applied, the curve became more sigmoid (open circles). The difference between the two curves might be due to incomplete voltage clamp caused by rapid sodium current as BEELER and ReUTER (1970 a, c) noted in the dog ventricle. Thus, the relationship in the presence of tetrodotoxin would be more reliable, with a steep increase of tension at potentials between -50 and $-20 \mathrm{mV}$. The mechanical threshold shifted a few $\mathrm{mV}$ to the positive side, although the potential where the maximum tension was attained was not modified. These and preceding results strongly suggest that not only the duration of normal action potential but also the potential level of the plateau markedly affects the twitch tension.

The relationship between the membrane voltage and current will be analysed elsewhere. 


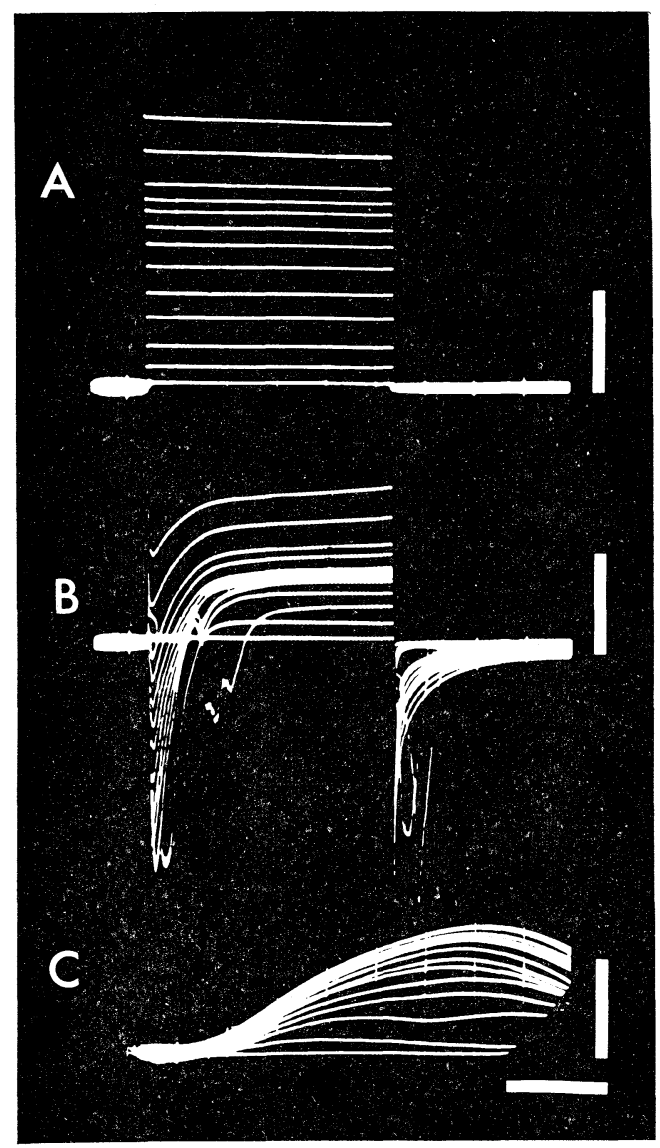

Fig. 5. Superimposed records of the membrane potential (A), current (B) and tension development (C) during voltage clamp steps. Horizontal bar, calibration of $400 \mathrm{msec}$, and vertical bars, calibrations of $30 \mathrm{mV}, 10 \mu \mathrm{A}$ and $0.2 \mathrm{~g}$ for voltage, current and tension records, respectively. For weak pulses above threshold, repetitive and break responses were produced.

\section{4) Time course of tension development during voltage clamp}

Since a biphasic contractile response consisting of an initial twitch with relaxation and a sustained contracture were common findings in the mammalian ventricles (MCGuigan, 1968; Wood et al., 1969; BeEler and Reuter, 1970 c), a similar biphasic response in the bullfrog ventricle was looked for with long pulses, but none was found. Figure 7 shows the time course of tension development when the membrane potential was shifted from the holding potential $(-70 \mathrm{mV})$ to various other voltage levels for four seconds. As noted before, the tension developed rapidly during the first second and, after a peak during the next or following seconds, gradually decreased towards the end of the pulse. The peak and 

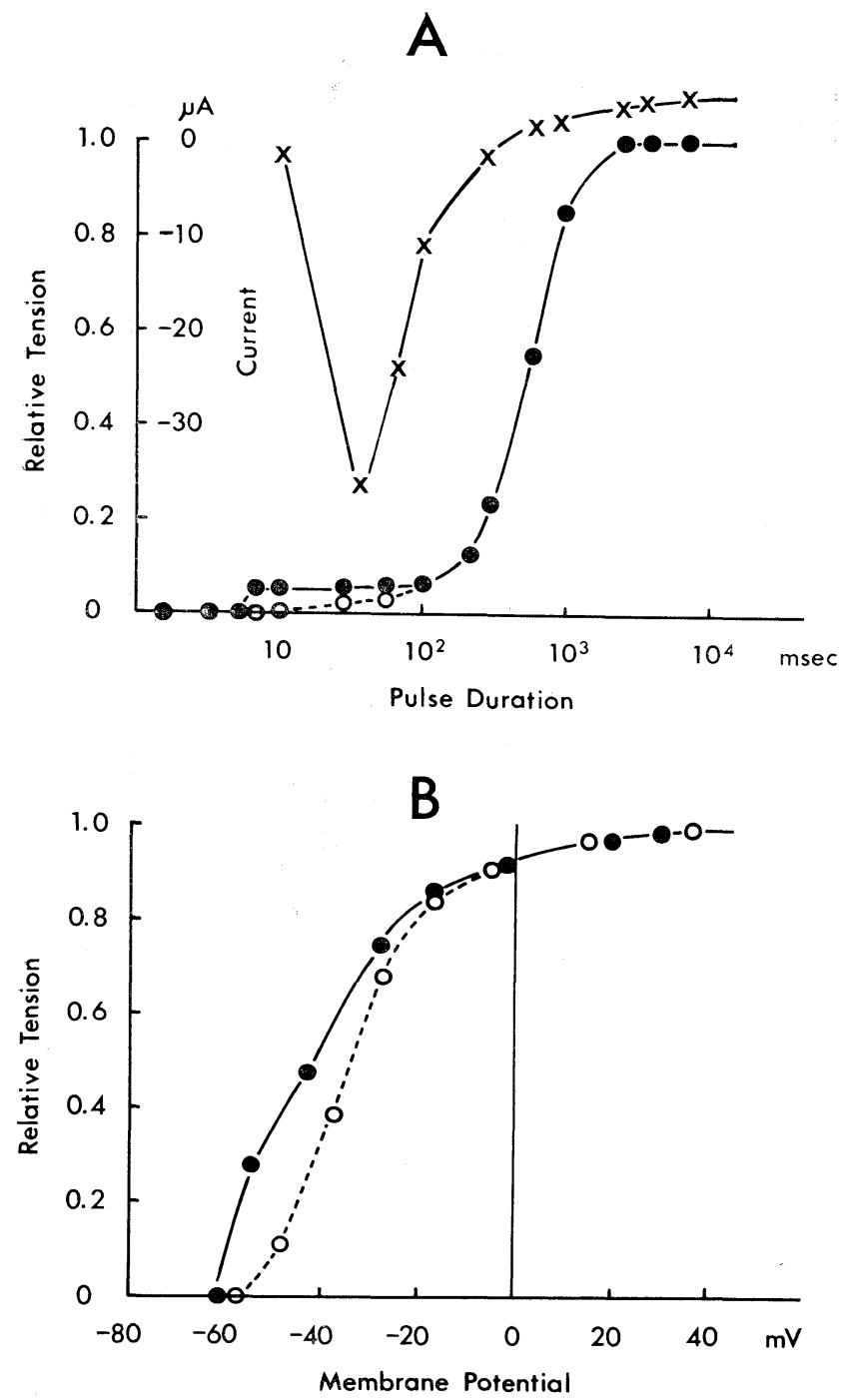

Fig. 6. A) Effects of pulse duration on peak tension. B) Relation between peak tension and membrane potential. Bullfrog ventricular trabeculae. Filled circles, peak tensions in normal condition, and open circles, those in the presence of tetrodotoxin $\left(10^{-6} \mathrm{~g} / \mathrm{ml}\right)$. Crosses show time course of the current in normal condition. Mean values for three series of experiments are plotted. The tension scales are normalized.

final tensions, as well as the rate of rise and fall of the tension, depended on the new membrane potentials, but the relations were not simple.

The time to peak tension was prolonged with increase in the amplitude of the depolarizing pulse, but this usually occurred in two steps. In some cases 


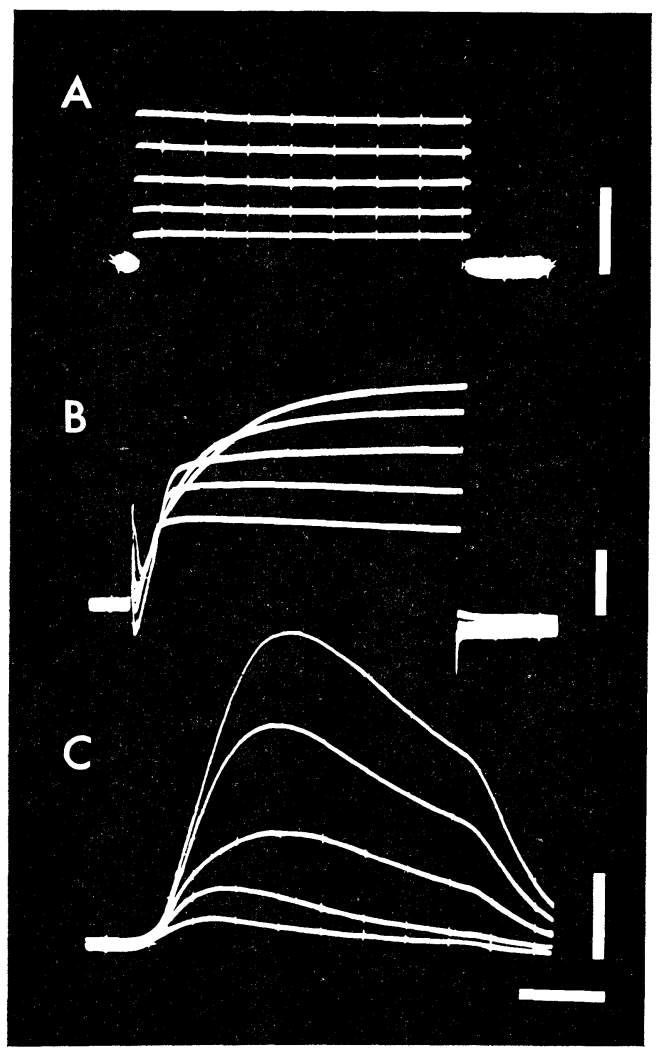

Fig. 7. Time courses of the current (B) and tension development $(\mathrm{C})$ at different potentials (A). Holding potential was $-70 \mathrm{mV}$. Clamp pulses of $4 \mathrm{sec}$ duration and variable intensities were applied. Horizontal bar, calibration of $1 \mathrm{sec}$; vertical bars, calibrations of $30 \mathrm{mV} ; 10 \mu \mathrm{A}$ and $0.08 \mathrm{~g}$ for $\mathrm{A}, \mathrm{B}$ and $\mathrm{C}$, respectively.

it was apparent that two peaks were elicited with a single depolarization of rather low voltages $(15-25 \mathrm{mV})$. However, since the first peak diminished after tetrodotoxin $\left(10^{-6} \mathrm{~g} / \mathrm{ml}\right)$, this was a simple artifact due to the rapid sodium current as noted. The prolongation of peak time, however, was still observed in this condition. This phenomenon must be noted since in the dog ventricle a shortening of peak time with pulse voltage was observed (BEELER and REUTER, $1970 \mathrm{c}$ ). Moreover, relaxation after the peak was considerably slower in the bullfrog ventricle, and no sign of a second rise of tension was observed even when the depolarizing pulse was increased up to $100 \mathrm{mV}$ and the duration was prolonged up to 120 seconds. 


\section{DISCUSSION}

Membrane currents and contractile responses of the ventricular trabeculae of the bullfrog have been studied under voltage clamp conditions. The principal results obtained are quite in accord with the preceding studies on the frog ventricle with the potassium contracture method (LÜTTGAU and NiEDERGERKE, 1958; LÜTTGAU, 1964), and also similar to those on the ventricular myocardium of warm-blooded animals with the voltage clamp method (Fozzard and Hellam, 1968; BEELER and REUTER, 1970 c), showing a S-shaped relationship between the membrane voltage and developed tension and a close correlation of the tension development with membrane currents.

Specific characteristics of the bullfrog ventricle, however, were 1) the lowness of the mechanical threshold which almost coincided with the threshold of sodium inward current, 2) the increase of time to peak tension with increasing strength of depolarizing pulse, 3 ) the slowness of relaxation during sustained depolarization, and 4) no differentiation of the first twitch and second tonic contractions.

Extensive studies by BEELER and ReUter (1970 a, b, c) with the voltage clamp method have clarified that on the dog ventricle the mechanical threshold of about $-35 \mathrm{mV}$ was identical to the potential at which the calcium inward current $\left(\mathrm{I}_{\mathrm{Ca}}\right)$ was activated while the threshold for the sodium inward current $\left(\mathrm{I}_{\mathrm{Na}}\right)$ was $-65 \mathrm{mV}$. Similar results of different thresholds for $I_{\mathrm{Na}}$ and $\mathrm{I}_{\mathrm{Ca}}$ were also reported for the guinea-pig myocardium (OCHI, 1970). For the bullfrog ventricle, on the other hand, the mechanical threshold as well as the threshold for tetrodotoxin insensitive current $(-58 \mathrm{mV})$ appeared considerably lower than those of the warm-blooded animals and almost coincided with $I_{\mathrm{Na}}$ threshold $(-62 \mathrm{mV})$. In some preparations the threshold for contraction appeared even lower than that for $I_{\mathrm{Na}}$. The low mechanical threshold agreed with the results obtained on the frog ventricle with the potassium contracture method (LüTtgaU and NiEDERgERKE, 1958; LüTTGAU, 1964).

The difference in mechanical threshold between the frog and mammalian ventricles could be due in part to the difference in ultrastructure of the myocardium. Staley and Benson (1968) and Antoni et al. (1969) demonstrated the absence of transverse tubules and the paucity of sarcotubules on the frog ventricle. Moreover, BEeLER and REUTER (1970 c) have revealed that for the dog ventricle the threshold of contraction as well as that of $I_{\mathrm{Ca}}$ shifts to a higher membrane potential in excess external calcium. Calcium excess media are also known to depress the function of sarcotubular systems and inhibit the inotropic effects of depolarization, repetitive stimulation and paired pulses (Goto et al., 1968; ANTONi et al., 1969). Thus, the nature of mammalian myocardium in excess calcium solution becomes quite similar to that of frog ventricles in normal Ringer solution, probably eliminating the sarcotubular functions after saturation of calcium in the systems.

On the cat, dog and sheep ventricular muscles, Morad and Trautwein 
(1968) showed that abolition of the action potential within the first $200 \mathrm{msec}$ by the voltage clamp could only alter the time course and amplitude of contraction and that the later phases of the action potential did not make any contribution to the tension development. Similar results were also obtained with rectangular depolarization clamp in the sheep Purkinje fiber (Fozzard and Hellam, 1968) and in the dog ventricular muscle (BEeler and REUTER, $1970 \mathrm{c}$ ), in which the peak tension appeared in a few hundred $\mathrm{msec}$ after the depolarization to $0 \mathrm{mV}$. In the case of the bullfrog ventricle, however, the peak tension was attained only after $2 \mathrm{sec}$ of the same depolarization, which was almost two times longer than the normal action potential. Thus, in the bullfrog ventricle whole phases of the action potential above mechanical threshold are estimated to contribute to the tension development, through the grade of contribution may vary depending on the phases. The observation on the frog ventricle that polarizing or depolarizing currents which were applied at the terminal phase of the action potential markedly modified the tension development (GoTO and BRooKs, 1970) will also support this view.

In the mammalian ventricles, when a depolarizing pulse was continued up to about $1 \mathrm{sec}$, there was a complete relaxation of tension even during strong depolarization (MCGUIGAN, 1968; BEELER and REuTER, 1970 a, b, c) and further prolongation of the pulse duration produced a second sustained contractile response (Kavaler, 1959; Morad and Trautwein, 1968; McGuigan, 1968). Wood et al. (1969) have shown that in sheep ventricle the second contractile response may strongly influence the twitch tension during the following depolarization. In our study on the bullfrog ventricle, on the other hand, neither a second response nor an after-inotropic effect was observed. Moreover, relaxation of the first twitch response was extremely slow when the depolarization was continued as noted. These observations strongly suggest the possibility that the relaxation between the first and second contractile responses in the mammalian myocardiums is ascribed to calcium-uptake function of the sarcotubular systems while in the bullfrog ventricle the first and second responses are fused because of the paucity of these systems. The lowness of mechanical threshold in the latter and the increase in time to peak tension with increasing pulse voltages also support this view. Thus, it is highly probable that depolarization or calcium accumulation in the cell triggers not only the muscle contraction but also its relaxation or return of calcium into stores in mammalian ventricles, while in the frog ventricle the relaxation starts only after the termination of the action potential in normal conditions. A puzzling problem and contradictory results on the correlation between the duration of action potential and contractile tension could be solved along this line. 


\section{REFERENCES}

Adrian, R. H., Chandler, W. K. and Hodgkin, A. L. (1969) The kinetics of mechanical activation in frog muscle. J. Physiol., 204: 207-230.

Anderson, N. C. (1969) Voltage clamp studies on uterine smooth muscle. J. Gen. Physiol., 54: $145-165$.

Antoni, H., Jacob, R. and Kaufmann, R. (1969) Mechanische Reaktionen des Frosch- und Säugetiermyokards bei Veränderung der Aktionspotential-Dauer durch Konstante Gleichstromimpulse. Pflügers Arch. Ges. Physiol., 306: 33-57.

BeEler, G. W. and Reuter, H. (1970 a) Voltage clamp experiments on ventricular myocardial fibres. J. Physiol., 207: 165-190.

Beeler, G. W. and Reuter, H. (1970 b) Membrane calcium current in ventricular myocardial fibres. J. Physiol., 207: 191-209.

BeEler, G. W. and Reuter, H. (1970 c) The relation between membrane potential, membrane currents and activation of contraction in ventricular myocardial fibres. J. Physiol., 207: 211-229.

Brady, A. J. (1964) Excitation and excitation-contraction coupling in cardiac muscle. Ann. Rev. Physiol., 26: 341-356.

Brown, H. F. and Noble, S. J. (1969) Membrane currents underlying delayed rectification and pace-maker activity in frog atrial muscle. J. Physiol., 204: 717-736.

CAputo, C. (1968) Volume and twitch tension changes in single muscle fibers in hypertonic solutions. J. Gen. Physiol., 52: 793-809.

Fozzard, H. A. and Hellam, D. C. (1968) Relationship between membrane voltage and tension in voltage-clamped cardiac Purkinje fibres. Nature, London, 218: 588-589.

Goto, M. and Brooks, C. MCC. (1970) Positive and negative inotropic action of polarizing current on the frog ventricle. Am. J. Physiol., 218: 1038-1045.

Goto, M., Sakamoto, Y. and Kawata, H. (1968) Premature extra-activation potentiation of contraction in the guinea-pig atrium. Japan. J. Physiol., 18: 238-255.

Kavaler, F. (1959) Membrane depolarization as a cause of tension development in mammalian ventricular muscle. Am. J. Physiol., 197: 968-970.

Kawata, H., Shibata, J. and Goto, M. (1969) A study on the coupling mechanism between action potential and contraction in the frog ventricle. Japan. J. Physiol., 19: 492-508.

LÜTTGAU, H. C. (1964) The role of calcium ions in excitation-contraction coupling. In Electrophysiology of the Heart, ed. by TACCARDI, B. and Marchetti, G. Pergamon, Oxford, pp. 87-95.

LÜttgau, H. C. and Niedergerke, R. (1958) The antagonism between Ca and $\mathrm{Na}$ ions on the frog's heart. J. Physiol., 143: 486-505.

McGuigan, J. A.S. (1968) Tension in ventricular fibers during a voltage clamp. Helv. Physiol. Pharmacol. Acta, 26: CR 362-363.

Morad, M. and Trautwein, W. (1968) The effect of the duration of the action potential on contraction in the mammalian heart muscle. Pflügers Arch. Ges. Physiol., 299: 66-82.

OCHI, R. (1970) The slow inward current and the action of manganese ions in guinea-pig's myocardium. Pflügers Arch. Ges. Physiol., 316: 81-94.

Reuter, H. and BeEler, G. W. (1969) Calcium current and activation of contraction in ventricular myocardial fibers. Science, N. Y., 163: 399-401.

Rougier, O., Vassort, G., Garnier, D., Gargouil, Y. M. and Coraboeuf, E. (1969) Existence and role of a slow inward current during the frog atrial action potential. Pfügers Arch. Ges. Physiol., 308: 91-110.

Rougier, O., VASSORT, G. and STÄMPfLI, R. (1968) Voltage clamp experiments on frog atrial heart muscle fibers with the sucrose gap technique. Pflügers Arch. Ges. Physiol., 301: 91108. 
Sandow, A. (1970) Skeletal muscle. Ann. Rev. Physiol., 32: 87-138.

Staley, N. A. and Benson, E. S. (1968) The ultrastructure of frog ventricular cardiac muscle and its relationship to mechanism of excitation-contraction coupling. J. Cell Biol., 38: 99-114.

VAN DeR Kloot, W. G. and Dane, B. (1964) Conduction of the action potential in the frog ventricle. Science, N. Y., 146: 74-75.

Weidmann, S. (1952) The electrical constants of Purkinje fibres. J. Physiol., 118: 348-360.

Wood, E. H., Heppner, R. L. and Weidmann, S. (1969) Inotropic effects of electric currents. I. Positive and negative effects of constant electric currents or current impulses applied during cardiac action potentials. II. Hypotheses: Calcium movements, excitationcontraction coupling and inotropic effects. Circulation Res., 24: 409-445. 